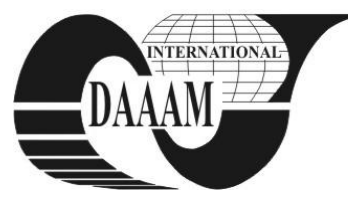

Annals of DAAAM for 2011 \& Proceedings of the 22nd International DAAAM Symposium, Volume 22, No. 1, ISSN 1726-9679 ISBN 978-3-901509-83-4, Editor B. Katalinic, Published by DAAAM International, Vienna, Austria, EU, 2011 Make Harmony between Technology and Nature, and Your Mind will Fly Free as a Bird

\title{
THE BEHAVIOUR OF LOW-ALLOY HIGH-STRENGTH STEEL AFTER DIFFERENT TYPES OF PROCESSING FOR DYNAMIC LOAD
}

\author{
JENICEK, S[tepan]; JIRKOVA, H[ana]; KUCEROVA, L[udmila] \& MASEK, B[ohuslav]
}

\begin{abstract}
Currently, there are new technological processes, which cannot be developed without knowledge of the technological properties of the material under specific, complex and dynamic conditions. One such application is the induction heating and moulding of a material within a few seconds to achieve temperature for warm moulding. This very short heating duration of only a few seconds has an effect on the development of the material structure, and this is reflected during deformation, depending on the stress-strain relationship. If these procedures are to be processed on the new modern types of steel, the development of technology and the measurement of mechanical properties must be done under the conditions of a real technological process. The article presents a method for determining the stress-strain relationship of AHSS steel processed using the QP-P process at a strain rate of $30 \mathrm{~s}^{-1}$. Key words: $Q-P$, strength, ductility, strain, dynamical behaviour
\end{abstract}

\section{INTRODUCTION}

The constant increase in demands on the mechanical properties of steels with the requirements for low cost are forcing manufacturers to create new types of unconventional structures that can achieve both high strength and good ductility. It is necessary to use unconventional methods of thermal or thermomechanical processing. One such method is the treatment process called Q-P (Edmonds et al., 2006). A martensitic structure with about $10 \%$ residual austenite can be achieved in low-alloy steels using this heat treatment. In these steels residual austenite is stored in the form of a film between the formations of martensitic plates or needles. During loading, the plastic properties of austenite allow small plastic deformation, which may enable the achievement of relatively high ductility in the bulk of the material. This allows cold or slightly heated material to be distorted. To detect the extent of the changes to the mechanical properties of the structure obtained by QP process in a related process of deformation using warm or slightly elevated temperatures, it is necessary to introduce new measuring techniques that allow the properties of the material to be precisely quantified. In this case, a new test was developed based on the stress-strain methodology. The entire active length of the trial bar is warmed evenly and tested by dynamic testing with strain rate $30 \mathrm{~s}^{-1}$.

\section{EXPERIMENT}

The experimental programme tested the measurement method combining rapid high-uniform heating of the sample with testing of the dynamic tensile test.

\subsection{Experimental material}

$42 \mathrm{SiCr}$ steel was selected for the experiment. The steel was processed (produced) using standard metallurgical processing and rolled into strips $18 \mathrm{~mm}$ thick. It is low-alloy steel with
$0.43 \% \mathrm{C}$ alloy $1.33 \% \mathrm{Cr}, 2 \% \mathrm{Si}$ and $0.59 \% \mathrm{Mn}$. Silicon alloy was used to reduce the precipitation of carbides. Manganese was also used to reduce the pearlite transformation and chromium to increase hardness and strength. Samples were processed using two different procedures; firstly, conventional heat treatment and then processing using Q-P process.

\section{Conventional heat treatment}

For conventional heat treatment, hardening followed by tempering was applied. Processing consisted of heating at 930 ${ }^{\circ} \mathrm{C}$ maintained for 25 minutes followed by hardening in water. Tempering was carried out at $250^{\circ} \mathrm{C}$ for 2 hours.

\section{Q-P process}

The Q-P process was used as the second heat treatment procedure. This is a new method of heat treatment for steel which allows high values of tensile strength to be reached without a significant decrease in the value of ductility (Kucerova et al., 2009). This process differs from the standard hardening process as the cooling is interrupted above the martensite finish temperature $\mathrm{M}_{\mathrm{f}}$. Then heating is carried out at a temperature just below the Ms temperature. At this temperature there is a several-minute delay, which leads to diffusion of carbon from martensite into austenite, which remains untransformed by the previous interrupted cooling process. For this experiment, the Q-P process was conducted with the following parameters: temperature of austenization $930^{\circ} \mathrm{C}$ with a dwell time of 20 minutes, followed by hardening in a salt bath to Mf temperature and heating in an oven to $250^{\circ} \mathrm{C}$ with a dwell time of 10 minutes.

\subsection{Mechanical testing}

It was necessary to design the optimal shape of the sample for precise mechanical testing, from the perspective of the possibility of rapid and uniform heating and from the perspective of achieving an adequate rate of deformation during the tensile test. For such procedures there is still no standard which would solve this problem. Therefore it was necessary to design the entire process, including optimizing the shape of the test bar using FEM simulation.

\subsection{Optimization of the shape of the test bar}

Three different shapes of test bars were designed with the support of FEM simulation. The main parameters included the optimization of a steady temperature field in the active part of the sample, while achieving a high strain rate. After measuring the temperature field in the axial direction, the form with an active length of $15 \mathrm{~mm}$ and diameter of $5 \mathrm{~mm}$ was evaluated as the best variant. The maximum relative deviation of the temperatures of the sample heating was below the defined level of $5 \%$ for the entire length of the active part of the bar, and in the entire temperature interval of heating. Temperatures were measured by thermocouples on the sample surface, while the temperature was monitored by an infrared camera. 


\subsection{Test parameters}

Various test temperatures were chosen to clarify the impact of a short-term temperature increase on the unstable multi-stage structure. In this case, two temperatures are compared: $25^{\circ} \mathrm{C}$ and $425^{\circ} \mathrm{C}$. The actual test consisted of heating to the temperature within 10 seconds and a 5 second dwell time at this temperature. Then followed exposure of the sample to tensile strain with the speed of the actuator at $0.45 \mathrm{~m} / \mathrm{s}$. The speed of the actuator presents a geometric deformation rate of $30 \mathrm{~s}^{-1}$ in the test-piece.

$$
v_{c}=L_{c} \cdot \dot{e}_{L_{c}}=15 \mathrm{~mm} \cdot 30 \mathrm{~s}^{-1}=\frac{450 \mathrm{~mm}}{\mathrm{~s}}
$$

Where $\mathrm{L}_{\mathrm{c}}$ is the length of the trial, $\mathrm{e}_{\mathrm{Lc}}$ deformation speed, $\mathrm{v}_{\mathrm{c}}$ actuator speed $(* * *, 2009)$. Whereas for the test a constant strain rate was required throughout the deformation, the test apparatus was used for achieving this high strain rate at the point of the beginning of the deformation.

\subsection{Metering mode}

To measure the dynamic material properties for this application a device was developed with strain sensors that can measure the force during the dynamic test. The force was measured by a strain member, where 4 resistance strain members were located connected to the bridge arrangement of two pairs of strain members on the opposite side of the device. This allows for compensation of both the temperature and any possible parasitic bending. During the test the actual deformation was recorded by a rapid video extensometer. This recording made it possible to evaluate the deformation of the sample based on the time and find the actual contraction of the sample. The video extensometer allows video with footage from the strain members to be synchronized. The video was filmed at a speed of $10000 \mathrm{fps}$, the sampling rate of the data from the force transducers were recorded at a rate of $100 \mathrm{kHz}$. High frequency data from the force sensor were chosen because of the interference filter, which causes resistance induction.

\section{RESULTS}

During the test the data were saved from the test machine, from the device and from the video extensometer. Data describing the temperature were obtained from the test apparatus, the actuator displacement and force versus time. Data from the video extensometer recorded data from the strain gauge element, i.e. a force curve, together with a pictorial record revealing changes in the geometry of the sample. First it was total elongation and local contraction. Engineering stress was calculated from the scanned data according to the wellknown formulas taken from literature (***, 1998; Wozniak, J. 2010).

To use the results of tensile tests to determine the formability or to input data into technological calculations and FEM analysis it is necessary to work with a diagram of the real stress - true stress - true strain, which can be obtained by converting the measured values (Fig.1). It is well known that heat treatment can increase ultimate strength at room temperature up to $1000 \mathrm{MPa}$.

\begin{tabular}{|l|l|l|l|l|}
\hline & $\begin{array}{l}\text { Tempera } \\
\text {-ture } \\
{\left[{ }^{\circ} \mathrm{C}\right]}\end{array}$ & $\begin{array}{l}\mathrm{R}_{\mathrm{p} 0,2} \\
{[\mathrm{MPa}]}\end{array}$ & $\begin{array}{l}\mathrm{R}_{\mathrm{m}} \\
{[\mathrm{MPa}]}\end{array}$ & $\begin{array}{l}\mathrm{A}_{15 \mathrm{~mm}} \\
{[\%]}\end{array}$ \\
\hline Starting position & 25 & 664 & 1050 & 22 \\
\hline Starting position & 425 & 470 & 806 & 22 \\
\hline Q-P process & 25 & 1562 & 1993 & 10 \\
\hline Q-P process & 425 & 1357 & 1600 & 14 \\
\hline Heat-treated samples & 25 & 1791 & 2077 & 13 \\
\hline Heat-treated samples & 425 & 1514 & 1753 & 13 \\
\hline
\end{tabular}

Tab. 1. Dynamic material properties of steel $42 \mathrm{SiCr}$ depending on the processing history

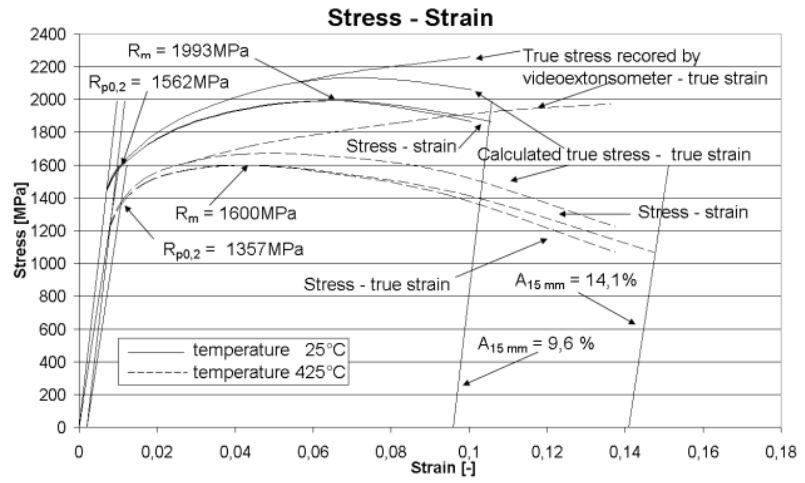

Fig. 1. Comparison of stress-strain diagrams: Q-P process, temperature $25^{\circ} \mathrm{C}$ and $425^{\circ} \mathrm{C}$

Decrease of the deformation tension is evident from the results of the experiment (Table 1). Significant here is a greater decrease in tensile strength from the QP process compared to conventional processing.

\section{CONCLUSION}

The aims of this experiment were to develop and optimize a new method for dynamic testing of materials under conditions of rapid heating of material to the temperatures of warm forming, or to moderate heating temperatures. Measurement was carried out in order to clarify the effect of short-term heat exposure on changes in the structure and mechanical, technological properties. The advantage of the proposed test methodology lies mainly in the fact that there is no limitation of the beginning of creation of the neck on the sample. This means it is possible to detect the current contraction until destruction. The dependence of the real stress - real strain can be evaluated from the collected data. These data, which are not yet available in the literature, accurately describe the behaviour of materials under specific process conditions. They can be therefore used in the design of new and unconventional technologies and also in their computer optimization using FEM simulations.

\section{ACKNOWLEDGEMENTS}

This paper includes results obtained within the project 1M06032 Research Centre of Forming Technology.

\section{REFERENCES}

Edmonds, D.; Rizzo, F.; De Cooman, B.; Matlou D. \& Speer, J. (2006). Quenching and partitioning martensite-A novel steel heat treatment, Materials Science and Engineering A, Vol. 438-440, (2006), 25-34, ISSN: 0921-5093

Kucerova, L.; Aisman, D.; Jirkova, H.; Masek, B. \& Hauserova, D. (2009). Optimization of Q-P Process Parameters with Regard to Final Microstructures and Properties, Annals of DAAAM for 2009 \& Proceedings of the 20th International DAAAM Symposium, 25-28th November 2009, Vienna, Austria, ISSN 1726-9679, ISBN 978-3-901509-70-4, Katalinic, B. (Ed.), pp. 1035-1036, Published by DAAAM International Vienna, Vinna

Wozniak, J.: (2010). Dopady revize normy ISO 6892-1 na praktické provádění tahových zkoušek Available from: http://www.sczl.cz/dokumenty/k06_05.pdf Accessed: 201005-15

*** (1998) CSN EN 10002-5 - Metallic materials - Tensile testing - Part 5, Czech Office for Standards, Metrology and Testing, July 1998

*** (2009) CSN EN ISO 6892-1:2009 - Metallic materials Tensile testing - Part 1, Czech Office for Standards, Metrology and Testing, February 2010 